\title{
The Transformation of Global Brands: An Abstract
}

\author{
Yu Yin Chang
}

\begin{abstract}
Currently, using the technique of data analysis to assist brand management is very popular. In the rich digital data market, there is a great deal of general literature on exploring customers' responses. However, specific guidance on what kind of global brands could survive in the high competitions is lacking. While the management of global brands has been extensively investigated, the transformation of global best brands is relatively unexplored. This paper introduces the possibility of text analytics to provide a framework for the profile and change of the successful global brands, by using Interbrand's Best Global Brands ranking report as a reference source (Interbrand 2017)

The world's best brands in the Interbrand's annual report are categorized and quantified in order to ascertain which brands evaluated by experts are the successful global brands. The results show that there are 166 different brands from 19 countries and 23 sectors from 2000 to 2016. The profiles of the successful global brand include C.O.O., industries, and other key factors. Moreover, text analytics was also used to investigate the keywords behind the transformation of Interbrand's Best Global Brand using the annual reports from 2006 to 2016. The results suggest that customer centric, strategy, experience, and technology are the key successful factors recently. The potential research directions are also addressed in this study.
\end{abstract}

\footnotetext{
Y.Y. Chang $(\bowtie)$

National Taiwan University, Taipei, Taiwan

e-mail: vivienneyuyin@gmail.com
} 